\title{
Alternative Fuels for Spark-Ignition Engines: Mixing Rules for the Laminar Burning Velocity of Gasoline-Alcohol Blends
}

\author{
Louis Sileghem,* Jeroen Vancoillie, Joachim Demuynck, Jonas Galle, and Sebastian Verhelst \\ Department of Flow, Heat and Combustion Mechanics, Ghent University, Sint-Pietersnieuwstraat 41, B-9000 Gent, Belgium
}

\begin{abstract}
Experimental measurements of the laminar burning velocity are mostly limited in pressure and temperature and can be compromised by the effects of flame stretch and instabilities. Computationally, these effects can be avoided by calculating one-dimensional, planar adiabatic flames using chemical oxidation mechanisms. Chemical kinetic models are often large, complex and take a lot of computation time, and few models exist for multi-component fuels. The aim of the present study is to investigate if simple mixing rules are able to predict the laminar burning velocity of fuel blends with a good accuracy. An overview of different mixing rules to predict the laminar burning is given and these mixing rules are tested for blends of hydrocarbons and ethanol. Experimental data of ethanol $/ n$-heptane and ethanol $/ n$-heptane/iso-octane mixtures and modeling data of an ethanol $/ n$ heptane blend and blends of ethanol and a toluene reference fuel are used to test the different mixing rules. Effects of higher temperature and pressure on the performance of the mixing rules are investigated. It was found that simple mixing rules that consider only the change in composition are accurate enough to predict the laminar burning velocity of ethanol/hydrocarbon blends. For the blends used in this study, a Le Chatelier's rule based on energy fractions is preferable because of the similar accuracy in comparison to other mixing rules while being more simple to use.
\end{abstract}

\section{INTRODUCTION}

The global energy supply has several problems. The main part of our energy sources are fossil fuels. These are not only depletable, but also the concentration of the sources is geographically unevenly distributed and, moreover, frequently located in politically unstable regions. Also, the growing world population, the increasing energy demand per capita, ${ }^{1}$ and the associated increase in greenhouse gas emissions, contributing to global warming, ${ }^{2}$ make the need for alternatives undeniable. This is particularly true for the transport sector, which is extremely dependent upon oil.

One of the major advantages of the current vehicle powertrain, the internal combustion engine, is that it can run on different fuels, making it a flex-fuel powertrain, in many cases only with a change of some parameters, such as ignition timing and injection duration. The flexibility of the internal combustion engine is already used, for example in the European Union where gasoline can contain up to $5 \%$ by volume of ethanol and up to $3 \%$ of methanol. This is performed to meet the biofuels directive of the European Union (2003/30/EC) and to increase the knock resistance of gasoline, with the alcohol serving as an octane booster. High concentration blends are also available, with E85 [85\% (v/v) ethanol and $15 \%(\mathrm{v} / \mathrm{v})$ gasoline] being the most common. As of February 2012, there are more than 8 million vehicles on U.S. roads that are able to run on E85, pure gasoline or any mixture of both. ${ }^{3}$ Although many such vehicles seldomly use E85, they offer the possibility of a transition to an alternative fuel economy. It can therefore be envisaged that a transition to alternative fuels could be an evolution rather than a revolution, with a major role for fuel blends enabling a soft start to an alternative transport energy economy.

Fuel blends can also have an economic advantage. Turner et al. ${ }^{4}$ presented the concept of ternary blends of gasoline, ethanol and methanol, in which the stoichiometric air/fuel ratio is controlled to the same value as that of conventional E85 alcohol- based fuel. It was shown that gasoline/ethanol/methanol blends formulated with a high proportion of methanol can be cheaper than gasoline on a cost per unit energy basis. Because methanol is cheap to produce, this is an alternative fuel technology that could actually be preferable financially for the customer without any government subsidy to encourage its uptake.

In the development of engines, engine cycle models have become indispensable tools because advanced engines incorporate a host of technologies and thus, many degrees of freedom for engine optimization. These engine cycle models are fuel-specific and need fuel-specific data. While many different models have been proposed for gasoline, this is much less the case for alternative fuels and almost completely lacking for blends of different fuels.

One of the key parameters to model the combustion of fuels in spark-ignition engines is the laminar burning velocity of the fuel. This is a physicochemical property of a fuel-air-residuals mixture and thus, a fundamental building block of any engine model. One way to obtain the laminar burning velocity is through experiments. Several experimental methods can be used to measure the laminar burning velocity of fuels: the onedimensional (1D) burner-stabilized flame, the counterflow flame, the expanding spherical flame, the Bunsen flame, etc. ${ }^{5}$ However, experimental measurements of the laminar burning velocity are mostly limited in pressure and temperature and are compromised by the effects of flame stretch and instabilities. Computationally, these effects can be avoided by calculating 1D, planar adiabatic flames using chemical oxidation mechanisms. The velocity of these flames is the laminar burning velocity by definition. Thus, kinetic models can be used to calculate the

Received: March 5, 2012

Revised: July 12, 2012

Published: July 19, 2012 
laminar burning velocity over a range of engine-like conditions. The drawback for fuel blends is that the kinetic models become very large and complex, with long calculation times as a result and that, in many cases, no models exist for blends of different fuels.

A possible solution would be to have accurate mixing rules for the laminar burning velocity, which can determine the laminar burning velocity of fuel blends out of the burning velocity of the fuel components without being computationally too demanding.

To compare mixing rules, an accurate determination of the laminar burning velocity of the fuel components and the laminar burning velocity of the fuel blends is needed. Unfortunately, there are few experimental measurements of fuel blends (with the exception for fuels with hydrogen addition), and there can be doubt in the accuracy of the measurements when measurements on different setups are compared. ${ }^{6}$ In the literature, few measurements of fuel blends are reported. Hirasawa et al. ${ }^{7}$ measured the laminar burning velocity of binary blends of ethylene $+n$-butene, ethylene + toluene and $n$-butane + toluene. Van Lipzig et al. ${ }^{8}$ considered binary and ternary mixtures of $n$ heptane, iso-octane and ethanol. Broustail et al. ${ }^{9}$ performed measurements with mixtures of butanol and ethanol with isooctane. Gülder et al. ${ }^{10}$ measured the laminar burning velocity of iso-octane + methanol and iso-octane + ethanol mixtures.

The next section provides an overview of mixing rules found in the literature. In the Results and Discussion, the validity of different mixing rules is tested, focusing on ethanol-hydrocarbon blends. The mixing rules are tested for experimental data of ethanol $/ n$-heptane and ethanol $/ n$-heptane/iso-octane mixtures and for modeling data of an ethanol $/ n$-heptane blend and blends of ethanol and a toluene reference fuel (TRF).

\section{COMPARISON OF MIXING RULES}

Burning velocities are mostly governed by the flame temperature, the activation energy and to a certain extent, the transport properties. ${ }^{7}$ There is thus kinetic, thermal and transport effects. Dependent upon the fuel, an enhanced reactivity can be expected, which is the case, for example, with hydrogen. ${ }^{11}$ A lower or higher adiabatic flame temperature, responsible for the thermal effect, can lead to another mixture reactivity, even assuming the same underlying reaction mechanism. Furthermore, dependent upon the diffusivities of the blend components, there can be a modification of the mixture concentration in the flame structure. ${ }^{12}$ The inherent difficulty in the development of a mixing rule is that various thermal and chemical effects may not be separable for fuel blends because of possible thermokinetic couplings. For this reason, mixing rules are not expected to be linear in the fuel blend composition. ${ }^{7}$

Because there are very few or even no chemical kinetic models of some fuel blends, it is interesting to explore if mixing rules of sufficient simplicity can be used, so that burning velocities of fuel blends can be readily estimated. In the literature, the following mixing rules were found:

Mixing Rule Based on Mole Fraction, Mass Fraction or Energy Fraction of the Components of the Fuels.

$$
u_{1, \text { blend }}(\Phi)=\sum_{i=1}^{n} \alpha_{i} u_{1, i}(\Phi)
$$

In the previous expression, $\alpha_{i}$ is either the mole fraction, mass fraction or energy fraction of the fuel components. The energy fraction can be calculated as follows:

$$
\alpha_{i}=\frac{\Delta c H_{i}^{\circ} x_{i}}{\sum_{i=1}^{n} \Delta c H_{i}^{\circ} x_{i}}
$$

$c H_{i}^{\circ}$ is the heat of combustion of the mixture components. $x_{i}$ is the mole fraction of the fuel components.

Mixing Rule Based on Le Chatelier's Rule. ${ }^{14}$

$$
u_{1, \text { blend }}(\Phi)=\frac{1}{\sum_{i=1}^{n} \frac{x_{i}}{u_{1, i}(\Phi)}}
$$

$x_{i}$ is the mole fraction of the fuel components.

Benedetto et al. ${ }^{14}$ used Le Chatelier's rule to predict the laminar burning velocity of hydrogen-methane blends and had a good agreement for lean and stoichiometric conditions, but for rich mixtures, there were more significant differences between the simulation results obtained with the detailed reaction scheme GRI-Mech version $3.0^{15}$ and the values predicted by Le Chatelier's rule.

Le Chatelier's rule is based on the principle that, if a chemical system at equilibrium experiences a change, the equilibrium shifts to counteract the imposed change and a new equilibrium is established.

Mixing Rule Developed by Hirasawa et al. ${ }^{7}$ Hirasawa et al. ${ }^{7}$ found for ethylene/n-butane, ethylene/toluene and $n$-butane/toluene mixtures that the flame temperature has the dominant influence on the burning velocity of the fuel blends at atmospheric pressure and that the kinetic coupling hardly affects the burning velocities of fuel mixtures because of limited interactions among the fragments of fuel decomposition either ahead of or in the flame zone during fuel combustion. An empirical mixing rule, dependent upon a mole fraction weighted average of the burning velocities and flame temperatures, was developed.

The adiabatic flame temperature of a pure fuel $\left(T_{\mathrm{f}, i}\right)$ can be expressed by

$$
T_{\mathrm{f}, i}-T_{\mathrm{u}}=\Delta T_{i}=\frac{Q_{i}}{n_{i} c_{\mathrm{p}, i}}
$$

$Q$ is the heat release per mole of fuel. $n$ is the total number of moles of the products (including diluents) per mole of fuel. $c_{\mathrm{p}}$ is the mean molar specific heat of the products. $T_{\mathrm{u}}$ is the unburned gas temperature.

In the same way, the flame temperature of a fuel blend can be expressed by

$$
\begin{aligned}
& T_{\mathrm{f}, \text { blend }}-T_{\mathrm{u}, \text { blend }}=\Delta T_{\text {blend }}=\frac{Q_{\text {blend }}}{n_{\text {blend }} c_{\mathrm{p}, \text { blend }}} \\
& Q_{\text {blend }}=\sum_{n}^{i=1} x_{i} Q_{i}
\end{aligned}
$$

$x_{i}$ is the mole fraction of the fuel component. Assuming that the total amount of moles of the combustion products and diluents is

$$
n_{\text {blend }}=\sum_{i=1}^{n} x_{i} n_{i}
$$

the adiabatic flame temperature of the fuel blend can be calculated with

$$
\Delta T_{\text {blend }}=\sum_{i=1}^{n} \frac{x_{i} n_{i} \Delta T_{i}}{n_{\text {blend }}}
$$

The burning velocity of the fuel constituent and the fuel blend can be approximated by

$$
u_{1, i}=\exp \left(-\frac{\tilde{T}_{\mathrm{a}, i}}{T_{\mathrm{f}, i}}\right)
$$

and

$$
u_{1, \text { blend }}=\exp \left(-\frac{\tilde{T}_{\mathrm{a}, \text { blend }}}{T_{\mathrm{f}, \text { blend }}}\right)
$$

where $\tilde{T}_{\mathrm{a}}$ is determined by a rearrangement of an expression for $u_{\mathrm{l}}$ with non-unity $L e$

$$
\rho_{\mathrm{u}} u_{1}=\left[\frac{\operatorname{Le}\left(\frac{\lambda}{c_{\mathrm{p}}}\right) B_{\mathrm{c}}}{Z e}\right]^{1 / 2} \exp \left(-\frac{T_{\mathrm{a}}}{2 T_{\mathrm{f}}}\right)
$$


where $\rho_{\mathrm{u}}$ is the unburned gas density, $\lambda$ is the thermal conductivity, $B_{\mathrm{c}}$ is the frequency factor, $T_{\mathrm{a}}$ is the activation temperature, and $Z e$ is the Zeldovich number. ${ }^{16}$ Assuming $\tilde{T}_{\mathrm{a}, \text { blend }}$ can be expressed in the same way as $\Delta T_{\text {blend }}$

$$
\tilde{T}_{\mathrm{a}, \text { blend }}=\sum_{i=1}^{n} \frac{x_{i} n_{i} \tilde{T}_{\mathrm{a}, i}}{n_{\text {blend }}}=-\sum_{i=1}^{n} \frac{x_{i} n_{i} T_{\mathrm{f}, i} \ln \left(u_{1, i}\right)}{n_{\text {blend }}}
$$

$u_{1, \text { blend }}$ can be calculated.

Finally, the expression for laminar burning velocity becomes

$$
\begin{aligned}
& u_{1, \text { blend }}=\prod_{i=1}^{n} u_{1, i}{ }^{\beta_{i}} \\
& \beta_{i}=\frac{x_{i} n_{i} T_{\mathrm{f}, i}}{n_{\text {blend }} T_{\mathrm{f}, \text { blend }}}
\end{aligned}
$$

The mixing rule developed by Hirasawa et al. predicted the experimental measurements very accurately for atmospheric laminar burning velocities of ethylene/ $n$-butane, ethylene/toluene and $n$-butane/toluene mixtures.

In the same way, Ji et al. ${ }^{17}$ found that the laminar burning velocity of $n$-dodecane/toluene and $n$-dodecane/methylcyclohexane mixtures at atmospheric pressure can be predicted using the laminar burning velocities and adiabatic flame temperatures of the neat components. It was found that, although the fuel initial consumption pathways of $n$ dodecane, toluene and methylcyclohexane and the resulting intermediates and radicals may be different for each neat component, the propagation of flames of binary fuels is mostly sensitive to the flame temperature through its influence on the main branching reaction $\mathrm{H}+$ $\mathrm{O}_{2} \rightarrow \mathrm{OH}+\mathrm{O}$. Kinetic couplings appeared to have a minor effect on flame propagation.

On the other hand, there may be fuel blends where chemical kinetic interactions have the biggest influence, e.g., hydrogen/methane mixtures. $^{11,12,18}$

There have been a lot of measurements of the laminar burning velocity of fuels in combination with hydrogen. The reason is that, because of the strong reactivity of hydrogen, an addition of hydrogen enhances flame propagation and extends the flammability limits of fuel/ air mixtures. Therefore, it has the potential to promote combustion efficiency and reduce pollutant and greenhouse gas emissions. ${ }^{11}$ The effects of hydrogen addition have been studied extensively using different methods and different fuels, such as methane, ethylene, acetylene, propane, $n$-butane, iso-octane, carbon monoxide and natural gas. ${ }^{2,19-24}$

Yu et al. ${ }^{25}$ found that the increase of burning velocity with hydrogen addition can be approximately linearly correlated with $R_{\mathrm{H}} \cdot R_{\mathrm{H}}$ is the ratio of the amount of hydrogen plus the stoichiometric amount of air needed for its oxidation, to the amount of fuel plus the remaining air left for its oxidation.

$$
R_{\mathrm{H}}=\frac{C_{\mathrm{H}}+\frac{C_{\mathrm{H}}}{\left(\frac{C_{\mathrm{H}}}{C_{\mathrm{A}}}\right)_{\mathrm{st}}}}{C_{\mathrm{F}}+\left[C_{\mathrm{A}}-\frac{C_{\mathrm{H}}}{\left(\frac{C_{\mathrm{H}}}{C_{\mathrm{A}}}\right)_{\mathrm{st}}}\right]}
$$

$C_{\mathrm{F}}, C_{\mathrm{A}}$ and $C_{\mathrm{H}}$ are the mole concentrations of the fuel, air and hydrogen addition.

Tang et al. ${ }^{12}$ found the same linear correlation for $n$-butane with hydrogen addition. With a sensitivity analysis, they showed that the kinetic effect is the most prominent, followed by the thermal effect, with the diffusion effect being minimal. Wu et al. ${ }^{11}$ did the same for the laminar burning velocities of mixtures of ethane, ethylene, acetylene and carbon monoxide with a small amount of hydrogen addition at atmospheric and elevated pressures. Effects of hydrogen addition were interpreted through an expression obtained with a one-step overall reaction and constant transport properties

$$
u_{1} \sim(\alpha L e)^{1 / 2} \exp \left(-\frac{T_{a}}{2 T_{a d}}\right)
$$

in which the Lewis number Le in combination with the thermal diffusivity $\alpha$, the activation temperature $T_{a}$, and the adiabatic flame temperature $T_{\mathrm{ad}}$ can be considered to represent the diffusion, kinetic and thermal effects. It was found that the approximately linear correlation also largely applies to ethane, ethylene and acetylene at atmospheric as well as elevated pressures and that, in most cases, hydrogen addition enhances burning velocity mainly through the modification of the activation temperature rather than the flame temperature. The linear correlation did not hold for carbon monoxide because of the strong catalytic effect of hydrogen on the oxidation of carbon monoxide.

It is not the purpose of the authors to give a full overview of the effect of hydrogen addition, and because it has been studied extensively, investigation of fuels in combination with hydrogen fall outside the scope of this study. The next section focuses on ethanol-hydrocarbon blends.

\section{RESULTS AND DISCUSSION}

First, measurements performed by van Lipzig et al. ${ }^{8}$ were used to compare different mixing rules because these measurements were performed using a flat plate burner and the heat flux method resulted in an accuracy of $\pm 1 \mathrm{~cm} / \mathrm{s}$. The measured laminar burning velocities of a mixture of $50 \%(\mathrm{v} / \mathrm{v})$ ethanol $+50 \%(\mathrm{v} / \mathrm{v})$ $n$-heptane and a mixture of $1 / 3(\mathrm{v} / \mathrm{v})$ ethanol $+1 / 3(\mathrm{v} / \mathrm{v}) n$ heptane $+1 / 3(\mathrm{v} / \mathrm{v})$ iso-octane at $338 \mathrm{~K}$ and atmospheric pressure are compared to the calculated laminar burning velocities using different mixing rules in Figures 1 and 2 .

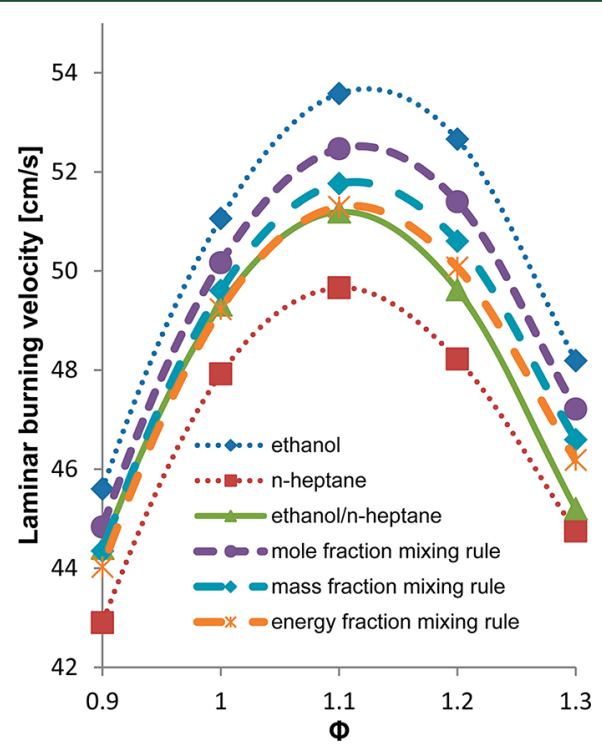

Figure 1. $u_{1}$ of ethanol, $n$-heptane and ethanol $/ n$-heptane blend as a function of $\Phi\left(p=1 \mathrm{bar}\right.$ and $\left.T_{\mathrm{u}}=338 \mathrm{~K}\right)$ and $u_{1}$ of the ethanol $/ n$-heptane blend calculated with the mole, mass and energy fraction mixing rules.

Calculations were made for equivalence ratios of $0.7-1.3$, but in Figures 1 and 2, the minimum equivalence ratio is 0.9 for the clarity of the figures and because the difference in laminar burning velocity in the $0.7-0.8$ range was $2 \mathrm{~cm} / \mathrm{s}$ at its maximum. From Figures 1 and 2, it is clear that the mole and mass fraction mixing rules and Le Chatelier's rule are not good enough to predict the laminar burning velocity of the binary mixture of ethanol and $n$-heptane for $\Phi>1$, although the maximum difference between the measurements and the calculated laminar burning velocities is only $2 \mathrm{~cm} / \mathrm{s}$. 


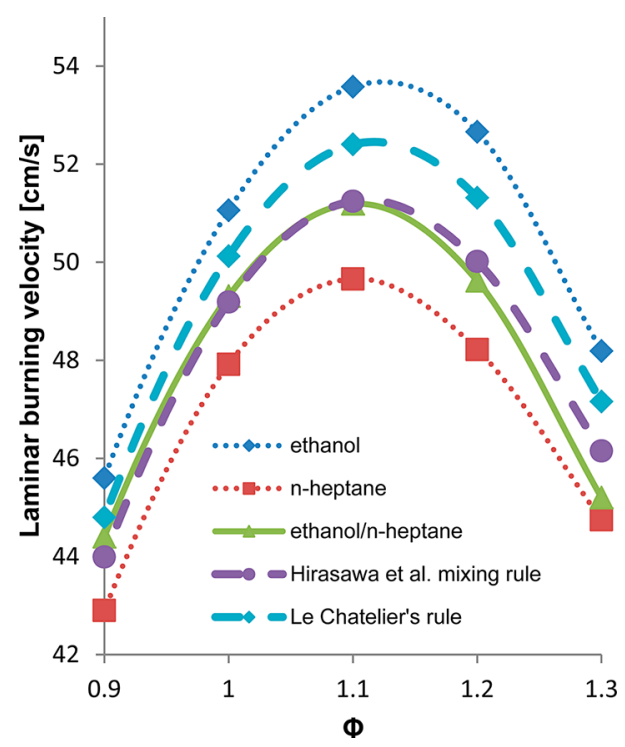

Figure 2. $u_{1}$ of ethanol, $n$-heptane and ethanol $/ n$-heptane blend as a function of $\Phi\left(p=1\right.$ bar and $\left.T_{\mathrm{u}}=338 \mathrm{~K}\right)$ and $u_{1}$ of the ethanol $/ n$-heptane blend calculated with the Hirasawa et al. mixing rule and Le Chatelier's rule.

The Hirasawa et al. mixing rule and the energy fraction mixing rule give good agreement with the measurements over the whole equivalence ratio. This interpretation can be confirmed when the root-mean-square error (RMSE) of the different mixing rules is compared (see Table 1). This indicates that the flame temperature is the dominant factor for the laminar burning velocity of the blends used in this study, as was found by Hirasawa et al. ${ }^{7}$

\section{Table 1. RMSE of the Different Mixing Rules}

\begin{tabular}{lc} 
& RMSE $(\mathrm{cm} / \mathrm{s})$ \\
mole fraction & 1.20 \\
mass fraction & 0.77 \\
energy fraction & 0.63 \\
Hirasawa et al. & 0.63 \\
Le Chatelier's rule & 1.15 \\
\hline
\end{tabular}

Hirasawa et al. validated their mixing rule only for binary mixtures of ethylene, $n$-butane or toluene. In Figure 3, the laminar burning velocity of a ternary mixture of $1 / 3(\mathrm{v} / \mathrm{v})$ ethanol $+1 / 3(\mathrm{v} / \mathrm{v}) n$-heptane $+1 / 3(\mathrm{v} / \mathrm{v})$ iso-octane at $338 \mathrm{~K}$ and atmospheric pressure is compared to the energy fraction mixing rule and the Hirasawa et al. mixing rule because these two rules gave the best results with binary mixtures. Again, the burning velocities can be estimated well with these two rules. The maximum error with the Hirasawa et al. mixing rule is $1.23 \mathrm{~cm} / \mathrm{s}$, and the maximum error with the energy fraction mixing rule is $1.36 \mathrm{~cm} / \mathrm{s}$.

The next goal was to investigate if these results can be extended to higher pressures, higher temperatures and multicomponent mixtures. Because gasoline blended with an alternative fuel is in fact a binary blend of a multi-component fuel and a pure fuel, it should be investigated if the mixing rules also work for blends of fuel that are a mixture of different components.

In the literature, such measurements of multi-component fuel blends at higher pressure and temperature are not yet reported.

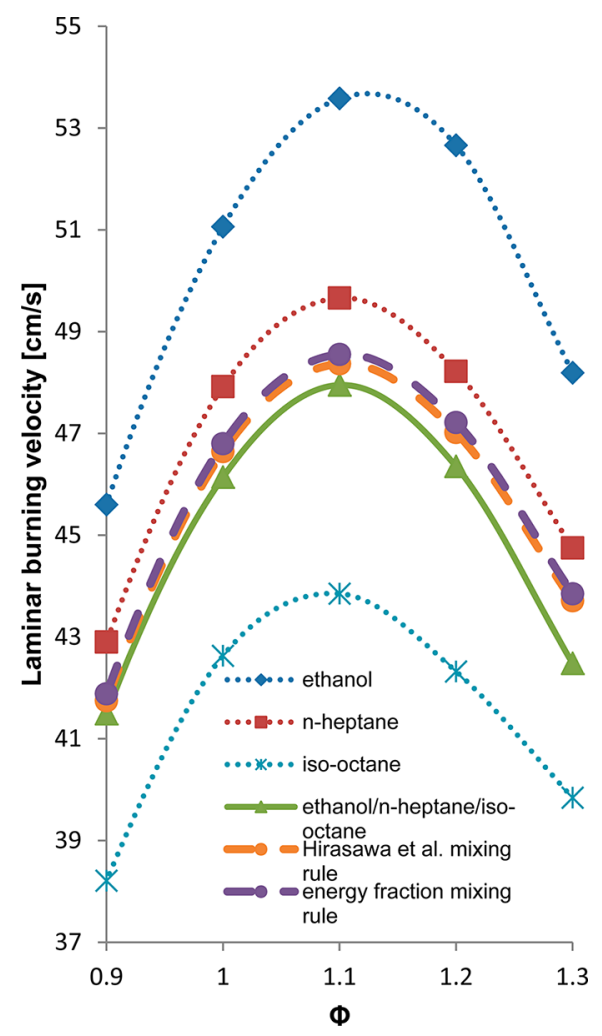

Figure 3. $u_{1}$ of ethanol, $n$-heptane, iso-octane and ethanol $/ n$-heptane/ iso-octane blend as a function of $\Phi\left(p=1 \mathrm{bar}\right.$ and $\left.T_{\mathrm{u}}=338 \mathrm{~K}\right)$ and $u_{1}$ of the ethanol $/ n$-heptane/iso-octane blend calculated with the energy fraction mixing rule and the Hirasawa et al. mixing rule.

Therefore, the chemical kinetic model by Andrae et al. ${ }^{26}$ was used to calculate laminar burning velocities of a TRF $[69 \%(\mathrm{v} / \mathrm{v})$ isooctane, $14 \%(\mathrm{v} / \mathrm{v}) n$-heptane, and $17 \%(\mathrm{v} / \mathrm{v})$ toluene], ethanol, and blends of ethanol and the TRF at higher temperature and higher pressure ( $600 \mathrm{~K}$ and $40 \mathrm{bar}$ ). This model is a semi-detailed mechanism containing 150 species and 759 reactions. It consists of a detailed description of toluene and ethanol oxidation and skeletal mechanisms of iso-octane and $n$-heptane. This model was chosen because it is one of the few kinetic models for ethanol-hydrocarbon fuels that was also validated with laminar burning velocities collected at elevated temperature and pressure and because it includes a detailed reaction mechanism for ethanol.

A toluene reference fuel was chosen to represent a gasoline, and the composition of the iso-octane/ $n$-heptane/toluene blend was chosen on the basis of the results in ref 27 , where the laminar burning velocities of this blend compared well to measurements of the laminar burning velocity of a real gasoline performed by Zhao et al. ${ }^{28}$

In Figure 4, the laminar burning velocity of E75 [75\% (v/v) ethanol and 25\% (v/v) TRF] and E20 [20\% (v/v) ethanol and $80 \%(\mathrm{v} / \mathrm{v}) \mathrm{TRF}$ ] at $600 \mathrm{~K}$ and $40 \mathrm{bar}$ is calculated with different mixing rules, and again, it is clear that the mole fraction mixing rule is not the right approach to predict the laminar burning velocity of multi-component fuels. Notice also the large difference in the burning velocity between the TRF and ethanol.

As seen in Figure 4, the energy fraction mixing rule and the Hirasawa et al. mixing rule give excellent agreement with the calculations from the chemical kinetic model, with the best results for the Hirasawa et al. mixing rule especially for the higher ethanol fraction. Notice that, as with the measurements by van 


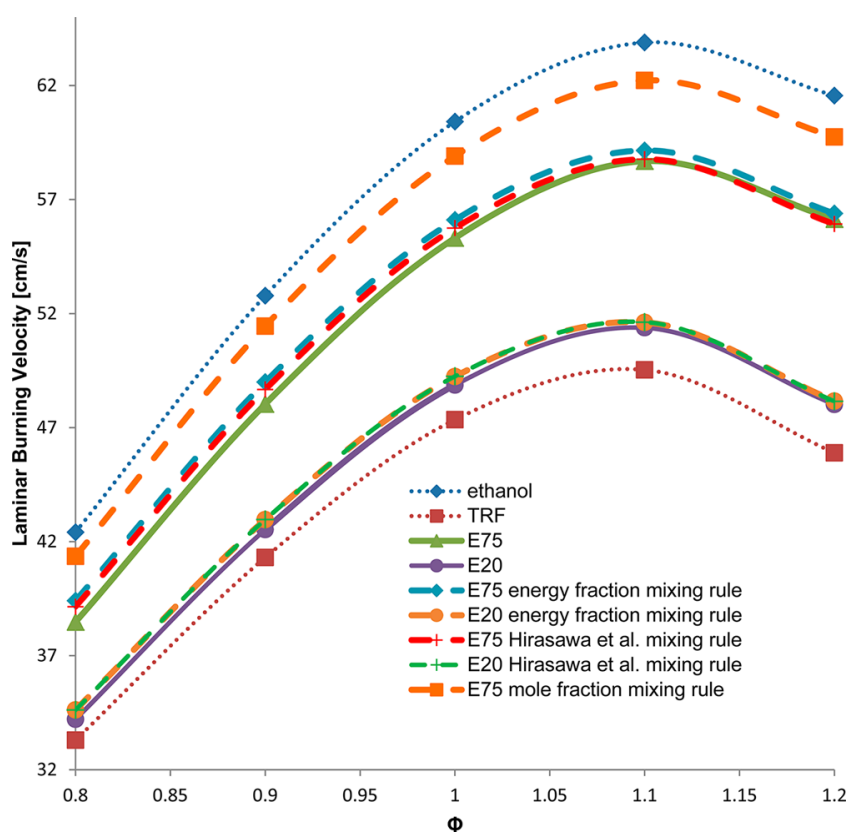

Figure 4. $u_{1}$ of ethanol, TRF, E75 and E20 as a function of $\Phi$ ( $p=40$ bar and $\left.T_{\mathrm{u}}=600 \mathrm{~K}\right)$ and $u_{1}$ of E75 and E20 calculated with the mole fraction mixing rule, the Hirasawa et al. mixing rule, and the energy fraction mixing rule.

Lipzig et al., the mixing rules overpredict the laminar burning velocity for most of the equivalence ratios.

Actually, it is not very surprising that the energy mixing rule gives similar results as the Hirasawa et al. mixing rule because it is based on the mole fraction and the heat of combustion of the fuel components, which can also be said of the flame temperature, the dominant factor in the Hirasawa et al. mixing rule.

For the type of fuels and range of equivalence ratios employed in this study, both the results with the energy mixing rule and the Hirasawa et al. mixing rule indicate that these two mixing rules can be used to predict the laminar burning velocity of multicomponent fuel blends (multiple fuels and "binary" blends of fuel blends) at higher temperature and pressure.

The best results are achieved with the Hirasawa et al. mixing rule, while the energy mixing rule has the greater simplicity as an advantage.

Given the fact that the energy fraction mixing rule and the Hirasawa et al. mixing rule, which are both based on the mole fraction and the heat of combustion, give the best results, one can wonder if Le Chatelier's rule could not be used if the energy fraction is used instead of the mole fraction

$$
u_{1, \text { blend }}(\Phi)=\frac{1}{\sum_{i=1}^{n} \frac{\alpha_{i}}{u_{1, i}(\Phi)}}
$$

with $\alpha_{i}$ being the energy fraction instead of the mole fraction.

In Figure 5, the energy fraction mixing rule, the Hirasawa et al. mixing rule, and Le Chatelier's mixing rule based on the energy fraction are compared for E75 at $600 \mathrm{~K}$ and 40 bar. In Figure 6, all of the different mixing rules are compared for E75 at $600 \mathrm{~K}$ and 1 bar. Here, the differences are more noticeable because the laminar burning velocities of pure ethanol and the TRF are more different from each other. As seen, the mixing rules all overpredict the laminar burning velocity, with the smallest overprediction for Le Chatelier's mixing rule based on the energy fraction.

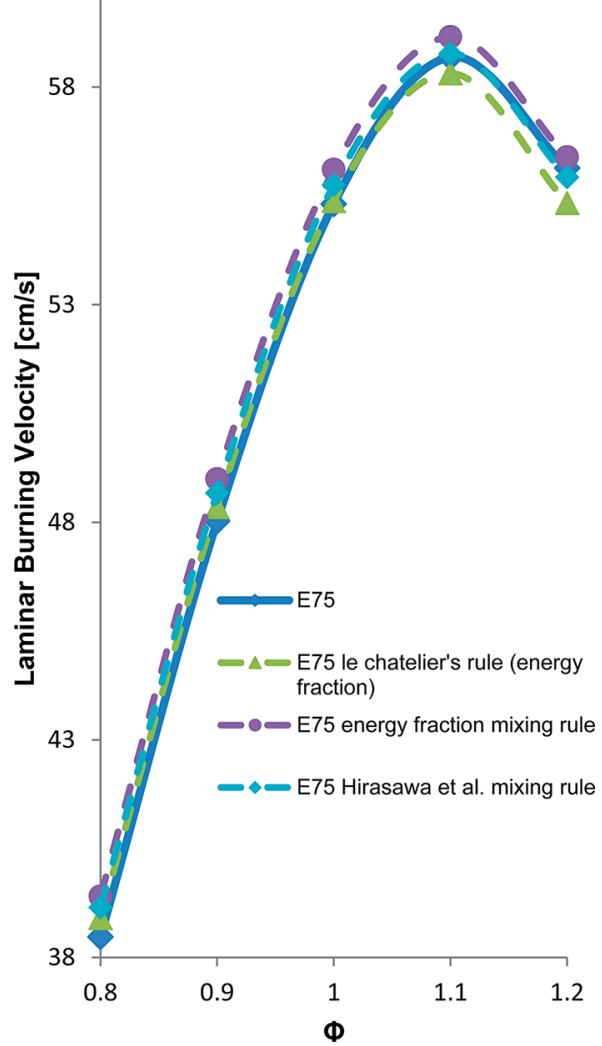

Figure 5. $u_{1}$ of E75 as a function of $\Phi\left(p=40\right.$ bar and $\left.T_{\mathrm{u}}=600 \mathrm{~K}\right)$ and $u_{1}$ of E75 calculated with different mixing rules.

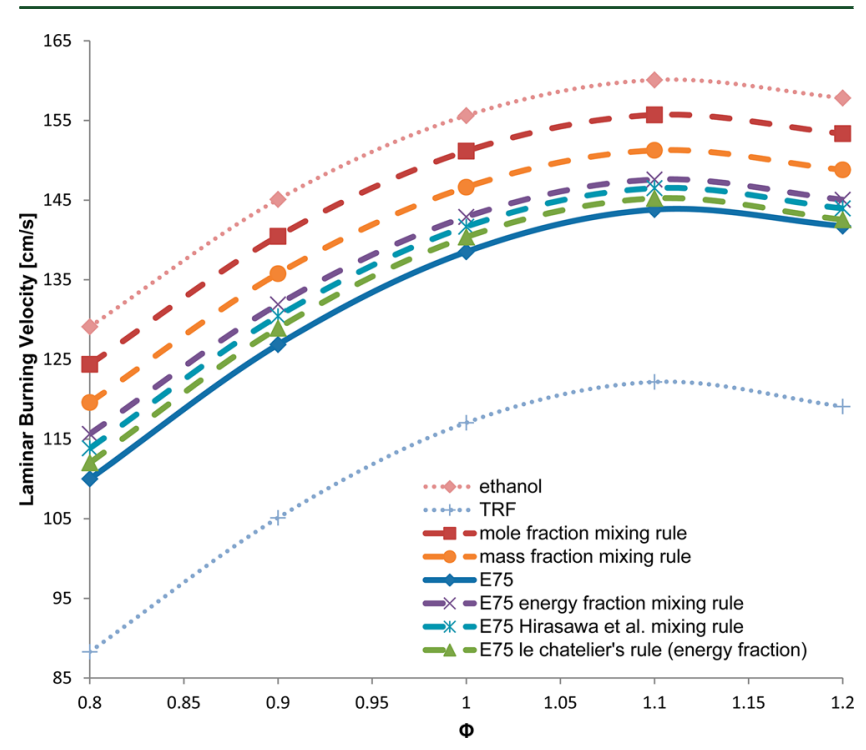

Figure 6. $u_{1}$ of E75 as a function of $\Phi\left(p=1\right.$ bar and $\left.T_{\mathrm{u}}=600 \mathrm{~K}\right)$ and $u_{1}$ of E75 calculated with different mixing rules.

The RMSEs (at $600 \mathrm{~K}$ and 1 bar) of the energy fraction mixing rule, the Hirasawa et al. mixing rule, and Le Chatelier's rule are $4.51,3.15$, and $1.70 \mathrm{~cm} / \mathrm{s}$, respectively. At 1 bar and $600 \mathrm{~K}$, the regression factors, $R^{2}$, are equal to 0.982 for Le Chatelier's rule, 0.937 for the Hirasawa et al. mixing rule, and 0.871 for the energy fraction mixing rule, which is clear from Figure 7. Thus, the agreement is best for Le Chatelier's mixing rule when data of the kinetic model by Andrae et al. ${ }^{26}$ is used. The same was found when the measurements by van Lipzig et al. were compared (not shown here). Because it is difficult to judge whether the results 


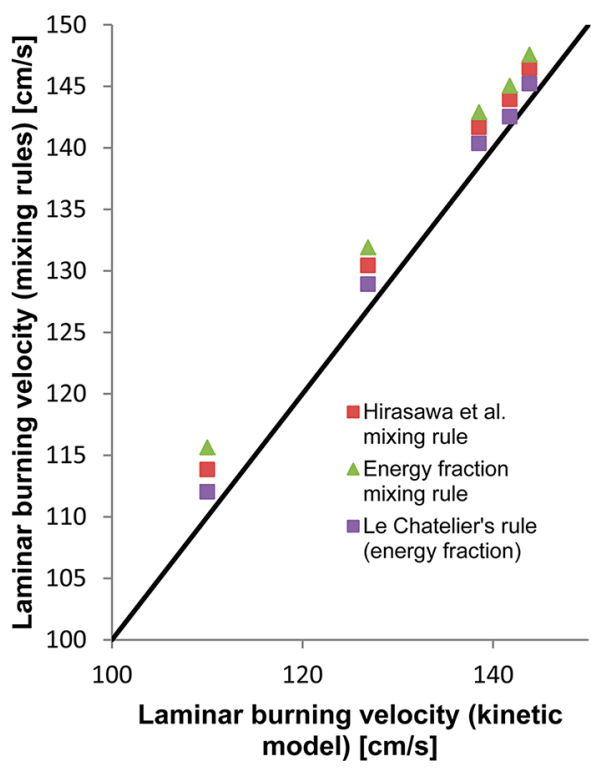

Figure 7. Laminar burning velocity of E75: kinetic model versus mixing rules.

using Le Chatelier's mixing rule based on the energy fraction are significantly different from the results with the Hirasawa et al. mixing rule, as a result of the uncertainty of the modeling data, an additional detailed chemical kinetic mechanism for the simulation of gasoline surrogate mixtures ${ }^{29}$ is used to calculate the laminar burning velocity of an ethanol $/ n$-heptane $[70 \%(\mathrm{v} / \mathrm{v})$ ethanol and $30 \%(\mathrm{v} / \mathrm{v})$ ethanol] blend at $600 \mathrm{~K}$ and $1 \mathrm{bar}$. This model has been assembled from existing Lawrence Livermore National Laboratory (LLNL) mechanisms for $n$-heptane, isooctane, toluene and $\mathrm{C} 5-\mathrm{C} 6$ olefins and validated using experimental data from shock tubes, stirred reactors and rapid compression machines. The results are shown in Figure 8. For the clarity of the figure, only the laminar burning velocities of the

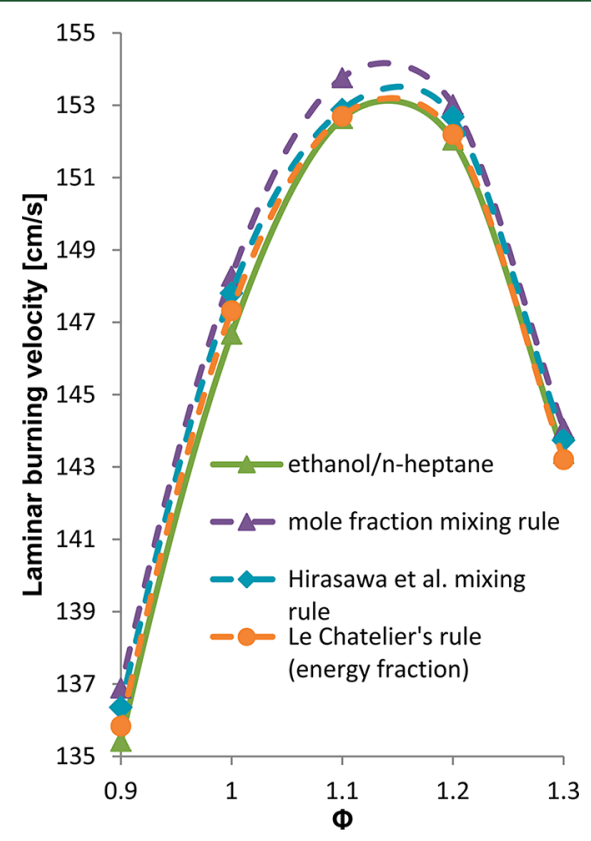

Figure 8. $u_{1}$ of ethanol $/ n$-heptane (LLNL mechanism) as a function of $\Phi\left(p=1\right.$ bar and $\left.T_{\mathrm{u}}=600 \mathrm{~K}\right)$ and $u_{1}$ calculated with different mixing rules. blend and the predictions by the mixing rules are shown. There is again an overprediction, with the least overprediction for Le Chatelier's rule and the largest overprediction for the energy fraction mixing rule. Notice that the differences are very small.

Because the same trend is seen in both the experimental and modeling data (overprediction of the laminar burning velocity) and because of the simplicity of Le Chatelier's rule, this rule is preferable until further validation.

The laminar burning velocity of fuel blends where chemical kinetic interactions have the biggest influence, e.g., hydrogen/ methane mixtures, cannot be predicted with the previous mixing rules, which is clear in Figure 9. Calculations of this mixture of $\mathrm{H}_{2}$

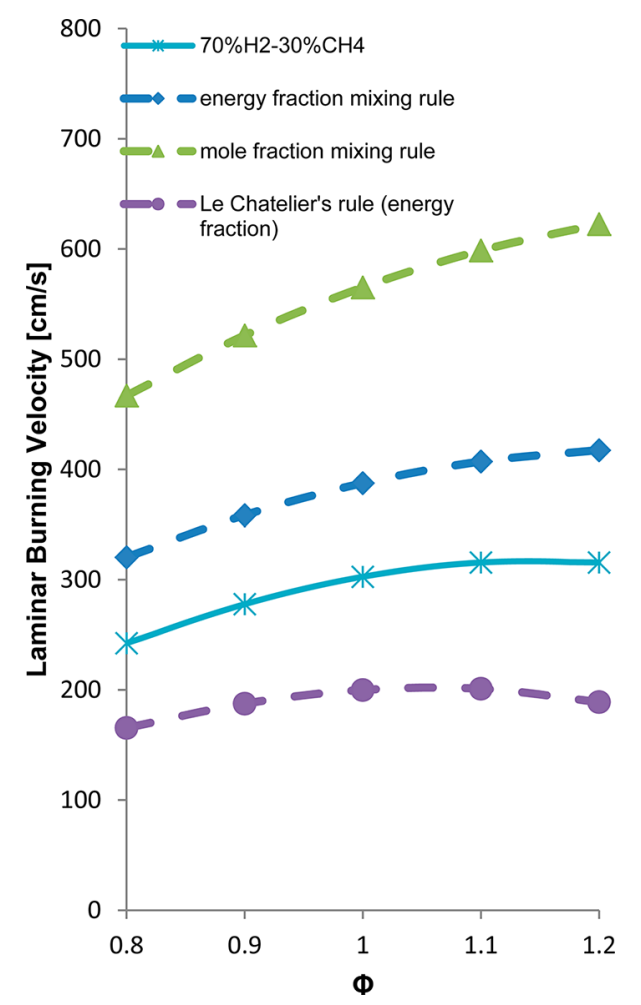

Figure 9. $u_{1}$ of $70 \% \mathrm{H}_{2}$ and $30 \% \mathrm{CH}_{4}$ as a function of $\Phi\left(p=1\right.$ bar and $T_{\mathrm{u}}$ $=600 \mathrm{~K})$ and $u_{1}$ calculated with different mixing rules.

and $\mathrm{CH}_{4}$ was performed with the GRI-Mech 3.0 mechanism. ${ }^{15}$ The influence of hydrogen addition is already extensively investigated, as mentioned previously.

\section{CONCLUSION}

In this study, different mixing rules to predict the laminar burning velocity of fuel blends were tested and compared to each other. Mixing rules are not expected to be linear in the fuel blend composition, proven by the poor predictions of the mole fraction and mass fraction mixing rules.

The energy fraction mixing rule, the mixing rule developed by Hirasawa et al., ${ }^{7}$ and the Le Chatelier's rule based on the energy fraction gave the best results, indicating that the flame temperature is the dominant factor for laminar burning velocity of the blends used in this study, as was found by Hirasawa et al. These three mixing rules performed very well for binary, ternary and multi-component fuels, and for "binary" blends of fuels, which are a blend of components, even at higher temperature and pressure. Le Chatelier's rule based on the energy fraction stood out above the rest for the data used in this study, in both accuracy 
and simplicity. However, because of uncertainty limits of both the experimental and modeling results, further validation is needed.

It was also shown that these mixing rules do not work for hydrogen-methane blends, but further investigation of fuels in combination with hydrogen fell outside the scope of this study.

\section{AUTHOR INFORMATION}

\section{Corresponding Author}

*E-mail: louis.sileghem@ugent.be.

\section{Notes}

The authors declare no competing financial interest.

\section{ACKNOWLEDGMENTS}

The research is funded by Ph.D. grants (SB-81139 and SB091221) of the Institute for the Promotion of Innovation through Science and Technology in Flanders (IWTVlaanderen) and Ph.D. grants (FWO09/ASP/030 and FWO11/ASP/056) of the Research Foundation-Flanders (FWO). This financial support is gratefully acknowledged.

\section{REFERENCES}

(1) Züttel, A.; Remhof, A.; Borgschulte, A.; Friedrichs, O. Hydrogen: The future energy carrier. Philos. Trans. R. Soc., A 2010, 368 (1923), 3329-3342.

(2) Houghton, J. T. Global Warming: The Complete Briefing, 3rd ed.; Cambridge University Press: Cambridge, U.K., 2004.

(3) United States Department of Energy (DOE). "E85: An Alternative Fuel", Alternative Fuels and Advanced Vehicles Data Center; U.S. DOE: Washington, D.C., 2012; http://www.afdc.energy.gov/afdc/ethanol/ e85.html (accessed Feb 23, 2012).

(4) Turner, J.; Pearson, R.; Purvis, R.; Dekker, E.; et al. GEM ternary blends: Removing the biomass limit by using iso-stoichiometric mixtures of gasoline, ethanol and methanol. SAE [Tech. Pap.] 2011, DOI: $10.4271 / 2011-24-0113$.

(5) Ranzi, E.; Frassoldati, A.; Grana, R.; Cuoci, A.; Faravelli, T.; Kelley, A. P.; Law, C. K. Hierarchical and comparative kinetic modeling of laminar flame speeds of hydrocarbon and oxygenated fuels. Prog. Energy Combust. Sci. 2012, 38 (4), 468-501.

(6) Vancoillie, J.; Verhelst, S.; Demuynck, J. Laminar burning velocity correlations for methanol-air and ethanol-air mixtures valid at SI engine conditions. SAE [Tech. Pap.] 2011, DOI: 10.4271/2011-240113.

(7) Hirasawa, T.; Sung, C. J.; Joshi, A.; Yang, Z.; Wang, H.; Law, C. K. Determination of laminar flame speeds using digital particle image velocimetry: Binary fuel blends of ethylene, $n$-butane, and toluene. Proc. Combust. Inst. 2002, 29, 1427-1434.

(8) van Lipzig, J. P. J.; Nilsson, E. J. K.; de Goey, L. P. H.; Konnov, A. A. Laminar burning velocities of $n$-heptane, iso-octane, ethanol and their binary and tertiary mixtures. Fuel 2011, 90 (8), 2773-2781.

(9) Broustail, G.; Seers, P.; Haalter, F.; Moréac, G.; MounaimRousselle, C. Experimental determination of laminar burning velocity for butanol and ethanol iso-octane blends. Fuel 2010, 90 (1), 1-6.

(10) Gülder, Ö. L. Laminar burning velocities of methanol, ethanol and isooctane-air mixtures. Symp. (Int.) Combust., [Proc.] 1982, 19 (1), 275-281.

(11) Wu, F.; Kelley, A. P.; Tang, C.; Zhu, D.; Law, C. K. Measurement and correlation of laminar flame speeds of $\mathrm{CO}$ and $\mathrm{C} 2$ hydrocarbons with hydrogen addition at atmospheric and elevated pressures. Int. J. Hydrogen Energy 2011, 36 (20), 13171-13180.

(12) Tang, C. L.; Huang, Z. H.; Law, C. K. Determination, correlation, and mechanistic interpretation of effects of hydrogen addition on laminar flame speeds of hydrocarbon-air mixtures. Proc. Combust. Inst. 2011, 33 (1), 921-928.
(13) van Lipzig, J. P. J. Flame speed investigation of ethanol, $n$-heptane and iso-octane using the heat flux method. Master's Thesis, Lund Institute of Technology, Lund, Sweden, 2010.

(14) Di Sarli, V.; Di Benedetto, A. Laminar burning velocity of hydrogen-methane/air premixed flames. Int. J. Hydrogen Energy 2007, $32(5), 637-646$.

(15) Smith, G. P.; Golden, D. M.; Frenklach, M.; Moriarty, N. W.; Eiteneer, B.; Goldenberg, M.; Bowman, C. T.; Hanson, R. K.; Song, S.; Gardiner, W. C., Jr.; Lissianski, V. V.; Qin, Z. http://www.me.berkeley. edu/gri_mech/.

(16) Law, C. K.; Sung, C. J. Structure, aerodynamics, and geometry of premixed flamelets. Prog. Energy Combust. Sci. 2000, 26 (4-6), 459505.

(17) Ji, C.; Egolfopoulos, F. N. Flame propagation of mixtures of air with binary liquid fuel mixtures. Proc. Combust. Inst. 2011, 33 (1), 955961.

(18) Bougrine, S.; Richard, S.; Nicolle, A.; Veynante, D. Numerical study of laminar flame properties of diluted methane-hydrogen-air flames at high pressure and temperature using detailed chemistry. Int. J. Hydrogen Energy 2011, 36 (18), 12035-12047.

(19) Law, C. K.; Kwon, O. C. Effects of hydrocarbon substitution on atmospheric hydrogen-air flame propagation. Int. J. Hydrogen Energy 2004, 29 (8), 867-879.

(20) Milton, B. E.; Keck, J. C. Laminar burning velocities in stoichiometric hydrogen and hydrogen/hydrocarbon gas mixtures. Combust. Flame 1984, 58 (1), 13-22.

(21) Sher, E.; Ozdor, N. Laminar burning velocities of $n$-butane/air mixtures enriched with hydrogen. Combust. Flame 1992, 89 (2), 214220.

(22) Mandilas, C.; Ormsby, M. P.; Sheppard, C. G. W.; Woolley, R. Effects of hydrogen addition on laminar and turbulent premixed methane and iso-octane-air flames. Proc. Combust. Inst. 2007, 31 (1), $1443-1450$.

(23) Dong, C.; Zhou, Q.; Zhao, Q.; Zhang, Y.; Xu, T.; Hui, S. Experimental study on the laminar flame speed of hydrogen/carbon monoxide/air mixtures. Fuel 2009, 88 (10), 1858-1863.

(24) Huang, Z.; Zhang, Y.; Zeng, K.; Liu, B.; Wang, Q.; Jiang, D. Measurements of laminar burning velocities for natural gas-hydrogenair mixtures. Combust. Flame 2006, 146 (1-2), 302-311.

(25) Yu, G.; Law, C. K.; Wu, C. K. Laminar flame speeds of hydrocarbon + air mixtures with hydrogen addition. Combust. Flame 1986, 63 (3), 339-347.

(26) Andrae, J. C. G. A kinetic modeling study of self-ignition of low alkylbenzenes at engine-relevant conditions. Fuel Process. Technol. 2011, 92 (10), 2030-2040.

(27) Andrae, J. C. G.; Brinck, T.; Kalghatgi, G. T. HCCI experiments with toluene reference fuels modeled by a semi-detailed chemical kinetic model. Combust. Flame 2008, 155 (4), 696-712.

(28) Zhao, Z.; Conley, J.; Kazakov, A.; Dryer, F. Burning velocities of real gasoline fuel at 353 and $500 \mathrm{~K}$. SAE [Tech. Pap.] 2003, DOI: $10.4271 / 2003-01-3265$.

(29) Mehl, M.; Pitz, W. J.; Westbrook, C. K.; Curran, H. J. Kinetic modeling of gasoline surrogate components and mixtures under engine conditions. Proc. Combust. Inst. 2011, 33 (1), 193-200. 